\title{
THE EFFECT OF ALKYLPHENOLS ON LOBSTER SHELL HARDENING
}

\author{
HANS LAUFER, ${ }^{1,2 *}$ MING CHEN, ${ }^{1,2}$ MICHAEL JOHNSON, ${ }^{1 \dagger}$ NESLIHAN DEMIR ${ }^{1 \ddagger}$ AND \\ JAMES M. BOBBITT ${ }^{3}$ \\ ${ }^{1}$ Department of Molecular and Cell Biology, University of Connecticut, Storrs, CT 06269-3125; \\ ${ }^{2}$ The Marine Biological Laboratory, Woods Hole, MA 02543; ${ }^{3}$ Department of Chemistry, University of \\ Connecticut, Storrs, CT 06269
}

\begin{abstract}
Alkylphenols, anthropogenic estrogenic endocrine disruptors in vertebrates, have been found in lobsters (Homarus americanus) in New England sites. We hypothesize that alkylphenols interfere in the shell hardening during molting. We used an in vitro cuticle bioassay to investigate the effects of 2 alkylphenolic compounds-2,4-bis-(dimethylbenzyl) phenol (compound 3) and bisphenol A (BPA; 4,4'-dihydroxy-2,2-diphenylpropane (also referred to as 4,4'-(propan-2-ylidene) diphenol)) - on tyrosine incorporation during the hardening of new cuticle following lobster molting. During sclerotization, both alkylphenols and cold tyrosine competed with $\mathrm{C}^{14}$-tyrosine incorporation in a concentration-dependent manner. This process was also phenoloxidase dependent, as treatment with phenylthiourea (PTU; a phenoloxidase inhibitor) significantly decreased $\mathrm{C}^{14}$-tyrosine incorporation. We also found that incorporation of $\mathrm{C}^{14}$-2,4-bis-(dimethylbenzyl) phenol during the shell hardening process was inhibited by cold alkylphenol, cold tyrosine, or PTU, and competition was concentration dependent. Furthermore, incorporation of tyrosine and derivatives into new cuticle decreased with time after molting from $27 \%$ incorporation 1 day after a molt to $6 \%$ by 4 days after a molt. In nonmolting cuticles, there was no incorporation of alkylphenol or tyrosine derivatives. When lobsters were injected with 2,4-bis-(dimethylbenzyl) phenol during the premolt stage, it took the shells $12 \pm 1$ days to harden sufficiently to resist deflection by $5 \mathrm{lb}$ pressure exerted by a pressure gauge, compared with $7 \pm 1$ days for control shells. Thus, shell hardening is delayed significantly by the presence of 2,4-bis-(dimethylbenzyl) phenol. The effects of this compound on shell hardening may result in lobsters' susceptibility to microbial invasion and, therefore, may contribute to the onset of shell disease.
\end{abstract}

KEY WORDS: American lobster, Homarus americanus, alkylphenols, bisphenol A, shell hardening, sclerotization, tyrosine, molting, lobster, cuticle

\section{INTRODUCTION}

Alkylphenols, such as 2,4-bis-(dimethylbenzyl) phenol (compound 3) and bisphenol A (BPA; 4,4'-dihydroxy-2, 2-diphenylpropane, sometimes referred to as $4,4^{\prime}$-(propan-2ylidene) diphenol) are of concern because of their toxicity and estrogenic endocrine disrupting capacity in vertebrates (Markey et al. 2001, vom Saal et al. 2007). They are used widely and disposed of from the manufacturing and breakdown of various products ranging from plastics, detergents, paints, and curing agents. Large amounts are released into the marine environment and are often long lasting, particularly at low oxygen concentrations. An estimated 600,000 mt alkylphenols are used annually (Naylor et al. 1992, Ying et al. 2002, Zintek 2012 per. comm, Langford et al. 2007), with estimates of up to 1 million mt produced more recently worldwide. Furthermore, BPA has an estimated production capacity worldwide of 3.7 million $\mathrm{mt} / \mathrm{y}$ (Mihaich et al. 2009). Annually, approximately $60 \%$ of the millions of metric tons of BPA and other alkylphenols that are produced end up in the aquatic environment via discharge from inefficient wastewater treatment plants or other release points (Warhurst 1995, Renner 1997, Ying et al. 2002), leading to well-known and widespread contaminants of rivers, oceans, and sediments (Hale et al. 2000, David et al. 2009). Levels of alkylphenols in sediments have been reported to be as high as $70,000 \mathrm{mg} / \mathrm{kg}$ in the United States (Ying et al. 2002), and were found in the urine of $95 \%$ of a U.S. human test population. They have been implicated in a number of health

*Corresponding author. E-mail: laufer@uconn.edu

$\dagger$ Current address: Radiology Department, Hospital of St. Raphael, 1450 Chapel Street, New Haven, CT 06511

$\$$ Current address: Department of Molecular Biology, Canakkale Onsekiz Mart University, 17020 Canakkale, Turkey

DOI: $10.2983 / 035.031 .0215$ problems, such as a reduction in fertility and meiotic disruptions (Calafat et al. 2005, Crain et al. 2007, vom Saal et al. 2007, Meyers et al. 2009).

Alkylphenolic contamination may also be a major contributor to the decreased American lobster (Homarus americanus, Milne Edwards) landings in Long Island Sound (LIS). Landings went from 3.7 million $\mathrm{lb}$ (1.68 million $\mathrm{kg}$ ) in 1998 to 0.6 million lb (0.27 million $\mathrm{kg})$ in Connecticut between 2003 and 2006 (Millstone Environmental Laboratory 2008, Laufer et al. 2012) showed that alkylphenols such as compound 3 and BPA are toxic to larvae at relatively low concentrations and interfere with larval metamorphosis. The financial effect of the lobster die-off has been devastating to the local fisheries and economy in the form of job losses as well as financial hardships.

Previously, we had examined the hemolymph and tissues of lobsters from across southern New England waters for the presence of selected alkylphenolic compounds. We detected alkylphenols in varying concentrations from undetectable levels to more than $4 \mu \mathrm{g} / \mathrm{g}(n=737)$. Thirty-nine percent of the lobsters were contaminated with at least 1 of 4 alkylphenols (Biggers \& Laufer 2004, Laufer et al. 2005b, Jacobs et al. 2008, Jacobs et al. 2012). We used a sensitive invertebrate bioassay using metamorphosis of trochophore larvae of a marine annelid, Capitella, which responded within $1 \mathrm{~h}$ of treatment, to determine levels of bioactive compounds, demonstrating that the compounds had juvenile hormone activity, similar to the crustacean juvenile hormone methyl farnesoate (Laufer et al. 1987, Biggers \& Laufer 1996, Biggers \& Laufer 1999, Biggers \& Laufer 2004). Juvenile hormones regulate metamorphosis and the quality of molting in insects (Riddiford \& Evans 1994). Our studies found that the following compounds previously found in lobster tissues (Jacobs et al. 2008, Jacobs et al. 2012)-2-t-butyl-4-(dimethylbenzyl) phenol, 2,6-bis-(t-butyl)-4-(dimethylbenzyl) phenol (also known 
as MON-0585, a Monsanto mosquito larvicide similar to Methoprene (Sacher 1971)), 2,4-bis-(dimethylbenzyl) phenol (compound 3), and 2,4-bis (dimethylbenzyl)-6-t-butylphenol, 4-cumylphenol, and BPA - had juvenile hormone activity in the Capitella bioassay. BPA was 20 times more active than the crustacean juvenile hormone methyl farnesoate (Biggers \& Laufer 2004, Laufer et al. 2012).

Molting is an important process of crustacean development during which sclerotization (tanning and cross-linking of protein and chitin) and shell hardening occur. Hypodermal cells underlying the cuticle secrete cuticular proteins into the subcuticular space (Vacca \& Fingerman 1975a, Vacca \& Fingerman 1975b, Vacca \& Fingerman 1983, Sugumaran et al. 1992, Dillaman et al. 2005). During sclerotization, the phenolic amino acid tyrosine is converted to quinones and their derivatives (Sugumaran et al. 1992), which are then oxidized by phenoloxidases (coppercontaining enzymes) to become highly reactive intermediates. These intermediates cross-link with histidyl residues of cuticular proteins and chitin, hardening the exoskeletons (Xu et al. 1997) (Fig. 1). For every tyrosine incorporated, as many as 4 protein molecules are bound. This process can be inhibited when phenoloxidase is irreversibly deactivated by phenylthiourea (PTU), a copper chelating agent (Laskin \& Piccinini 1986).

We hypothesize that alkylphenols could play a role in crustacean molting, notably affecting sclerotization by interfering with tyrosine incorporation into the cuticle during shell hardening. Here, we investigate whether alkylphenols (compound 3 and BPA) compete with tyrosine incorporation into cuticles that were monitored during and after a molt. After a molt, radioactivelabeled tyrosine ( $\mathrm{C}^{14}$-tyrosine) and radioactive-labeled compound 3 ( $\mathrm{C}^{14}$-2,4-bis-(dimethylbenzyl) phenol) were used to compete with unlabeled tyrosine and alkylphenols (either compound 3 or BPA) which reduced radioactive compound incorporation into new cuticle. The levels of competition by the alkylphenols as well as tyrosine incorporation into cuticles were monitored during and after a molt. Competition of alkylphenols to compete with incorporation of tyrosine and its derivatives into the new cuticle was measured, and the time dependence of the level of competition after a molt was determined. We also measured effects of in vivo shell hardening using a pressure gauge to determine the number of days required after a molt for the shell to resist $5 \mathrm{lb}$ pressure without deformation. Any changes in shell structure may delay shell hardening. A delay or change in shell structure may facilitate the invasion of lobsters by microorganisms, making them more susceptible to shell disease.

\section{MATERIALS AND METHODS}

\section{Animals}

Forty-eight lobsters were used in the current study; preliminary studies performed earlier gave consistently similar results but are not reported here. The lobsters used were collected from LIS, Connecticut, Massachusetts, and Rhode Island (see Jacobs et al. 2012). The animals (average weight, $338.6 \mathrm{~g}$; carapace length, $73.9 \mathrm{~mm}$ ) were maintained in cooled flowthrough seawater $\left(18 \pm 2^{\circ} \mathrm{C}\right)$ in $\mathrm{A}$-frame tanks at the Marine Biological Laboratory in Woods Hole, MA, and in living stream tanks with closed recirculating seawater equipped with aeration and biofilters at the University of Connecticut. The animals were fed 3 times per week with squid or fish. They were eyestalk ablated to induce molting by removing the sinus gland $\mathrm{X}$-organ complex, which produces a molt-inhibiting hormone.

\section{Chemicals}

The following chemicals were purchased from Sigma-Aldrich: 2,4-bis-(dimethylbenzyl)phenol, BPA (4,4' -dihydroxy-2,2-diphenylpropane, sometimes referred to as $4,4^{\prime}$-(propan-2-ylidene) diphenol), PTU, and tyrosine. $\mathrm{C}^{14}$-tyrosine and $\mathrm{C}^{14}$-benzoic acid were purchased from MP Biomedicals, Inc. (Irvine, CA). Scintillation fluid, methyl magnesium bromide, phenol, tert-butyl
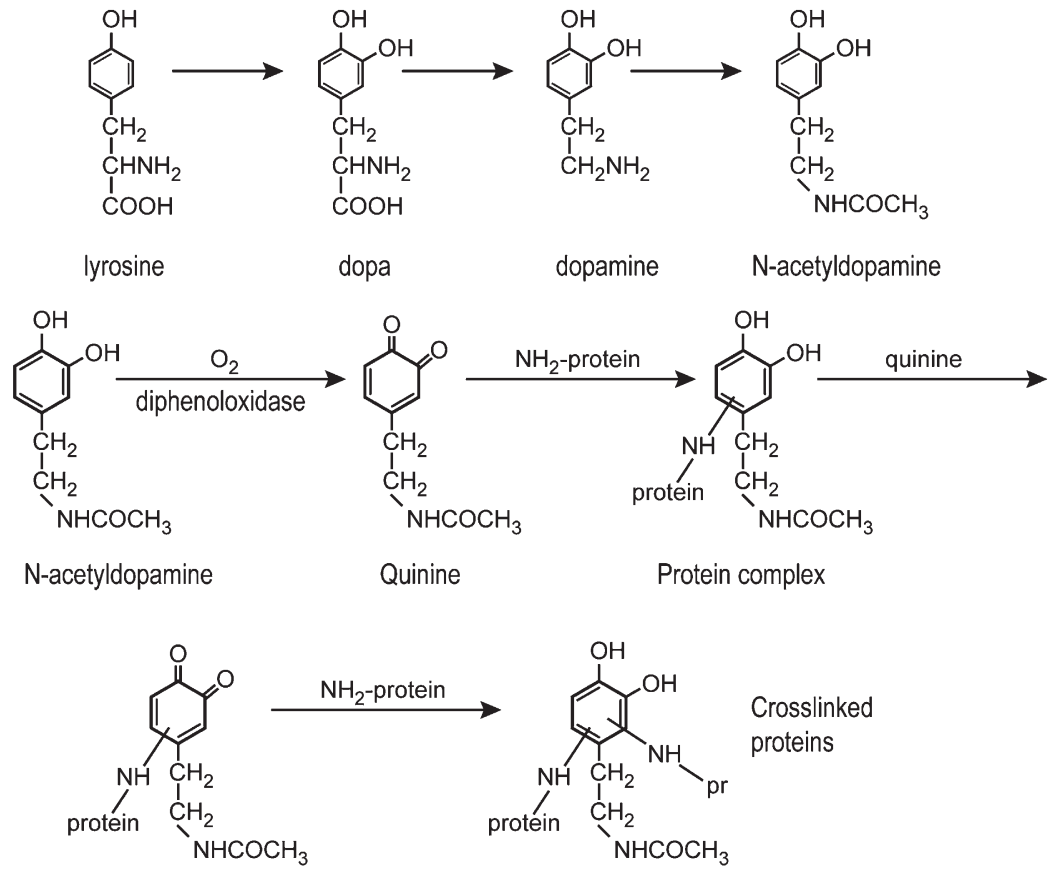

Figure 1. Biochemical reactions involved in sclerotization and the linking of tyrosine metabolites (Matthews \& Van Holde 1990, Xu et al. 1997). 
chloride, zinc chloride, and ethanol were purchased from Fisher Chemical. Diazomethane was prepared from Aldrich Diazalid by normal procedures. Salinity was maintained at about $30 \pm 2 \%$ using Coral Reef Red Sea Salt Mix using a Vitalsine refractometer to adjust salinity.

\section{Synthesis of C $C^{14}$-2,4-Bis-(Dimethylbenzyl) Phenol, Compound 3}

Diazalid (N-methyl-N-nitroso-p-toluenesulfonamide) was dissolved in dry ether and added slowly to a mixture of $\mathrm{KOH}$ pellets, distilled water, and 2-(2-ethoxyethoxy) ethanol at $70^{\circ} \mathrm{C}$. After distillation using the Aldrich Chemical Co. Diazomethane Apparatus, we obtained diazomethane. The distilled diazomethane solution was then added to benzoic acid that had been labeled $(0.5 \mu \mathrm{Ci} / \mathrm{mL})$ with $\mathrm{C}^{14}$ in the carboxylic carbon (step 1, Fig. 2) and then dissolved in dry ether. After $2 \mathrm{~h}$, the solvent was distilled under a stream of dry nitrogen to give $5 \%$ benzoic acid and 95\% labeled methyl benzoate, methyl alpha- $\mathrm{C}^{14}$ benzoate (step 2, Fig. 2). Labeled methyl benzoate was then added dropwise to a stirred solution of methyl magnesium bromide and mixed with dry ether in a Grignard reaction. The mixture was stirred overnight, during which a heavy white precipitate formed that settled to the bottom. The top ether layer was decanted, and the white layer was washed with dry ether. The combined ether layers were evaporated to dryness under a stream of nitrogen, which yielded $95 \%$ of labeled 2-phenyl-2-propanol (step 2). This phenylpropanol (step 3, Fig. 2) was added to 2-tert-butylphenol and toluenesulfonic acid ion exchange resin (Amberlyst-15), and stirred (no solvent) and heated to $65^{\circ} \mathrm{C}$. The oily mixture was dissolved in pentane, and the pentane layer was "pipetted" to a clean flask. The resin was washed with 5 more samples of the pentane and 1 portion of ether. The combined organic phases were washed with $5 \%$ aqueous $\mathrm{NaHCO}_{3}$ and dried over $\mathrm{Na}_{2} \mathrm{SO}_{4}$. The organic solvents were removed from the drying agent by pipette, and the drying agent was washed with fresh dry ether. The mixture was then placed in a distillation flask and evaporated to dryness under nitrogen. It was then distiled in a Kugelrohr (Buchi model 580 ) with a vacuum of $0.3 \mathrm{~mm}$. Excess undesired compound was distilled and collected into the first bulb at $100^{\circ} \mathrm{C}$. The temperature was then slowly raised to $160^{\circ} \mathrm{C}$ when the desired (2-phenylisopropyl)-phenol was distilled and collected (step 4, Fig. 2). This product was washed into a vial with ether, and the ether was evaporated under nitrogen. This is a known reaction, but to ou knowledge this was the first time it has been carried out with radioactivity (Welch \& Drake 1938). The final conversion to

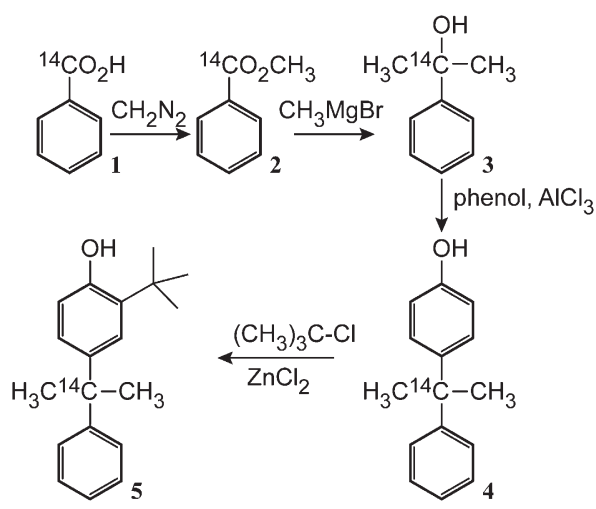

Figure 2. Synthesis of $\mathrm{C}^{14}$-labeled 2,4-bis-(dimethylbenzyl) phenol (compound 3) in 5 steps. 4-(2-phenyl-isopropyl)-2-tert-butylphenol, (step 5, Fig. 2), with tert-butyl chloride and zinc chloride, was carried out in this laboratory to produce compound 3-2,4-bis-(dimethylbenzyl) phenol - in radioactive form (Fig. 2) (see also Biggers \& Laufer 2004).

\section{Radioactive Tyrosine/Alkylphenol Incorporation}

For the in vitro culture experiments, we sacrificed lobsters during the molt between $2 \mathrm{~h}$ and $8 \mathrm{~h}$ after ecdysis, and cut the newly molted cuticle into $0.2-0.3-\mathrm{g}$ pieces. Other samples were taken at 1,2, and 4 days after a molt. We cultured each cuticle piece in 1 well of a 24-well culture plate with $500 \mu \mathrm{L}$ Pantin's solution (Pantin 1934) (30.65 g NaCl, $0.99 \mathrm{~g} \mathrm{KCl}, 1.82 \mathrm{~g} \mathrm{CaCl}_{2}$. $2 \mathrm{H}_{2} \mathrm{O}, 5.04 \mathrm{~g} \mathrm{MgCl}_{2} \cdot 6 \mathrm{H}_{2} \mathrm{O} / \mathrm{L}$, pH to 7.0). Each sample was then exposed to $10 \mu \mathrm{L}$ radioactively labeled tyrosine $(0.1 \mu \mathrm{Ci} / \mathrm{mL})$ or $\mathrm{C}^{14}$-2,4-bis-(dimethylbenzyl) phenol ( $\mathrm{C}^{14}$-compound 3; 0.02 $\mu \mathrm{Ci} / \mathrm{mL}$ ) for incorporation studies. In parallel experiments, tissue samples were incubated with a radioactive precursor and one "competitor" (cold tyrosine, cold compound 3, 2,4-bis(dimethylbenzyl) phenol, BPA, or PTU). Specimens were incubated on a shaker for $4 \mathrm{~h}$ at room temperature, then fixed in $1 \mathrm{~mL}$ ethanol and washed 3 times with Pantin's solution. After separation of cuticle and epidermis, cuticle samples were transferred to scintillation vials with $2 \mathrm{~mL}$ scintillation fluid, were left in vials overnight, and were counted the next day.

\section{Injection of lobsters in Vivo}

Premolt lobsters were previously eyestalk ablated 10-12 days before injection with either $0.2 \mathrm{~mL}$ peanut oil (controls) or $0.2 \mathrm{~mL}$ $2 \mathrm{mM}$ compound 3 in peanut oil suspension (experimental). Injections were done weekly until lobsters molted. Injections were performed into the abdomen at the junction of the soft cuticle of the posterior abdominal leg attachments.

\section{Shell Hardness Measurements}

Measurements were carried out on the anterior dorsal shells of molted lobsters that were injected with peanut oil (control group) or compound 3 (experimental group). The same dorsal intact carapace area was tilted to subject it to $5 \mathrm{lb}$ pressure by a pressure gauge to determine whether the shell was able to resist shell deformation. Tests were performed using a size 0 cork attached to the Pelouze model $\mathrm{K}$ pressure gauge (manufactured by a division of Healthometer, Inc.).

\section{Statistical Analysis}

The lobsters were usually acclimated to the laboratory and eyestalk ablated. This means that they were usually maintained for about a month or more until they molted. No geographical difference in the sources of the lobsters were observed or noted. Results are presented as a mean $\pm \mathrm{SD}$. A 1-way ANOVA was used to analyze the data statistically. Values were considered significant at $P<0.05$, and highly significant at $P<0.01$ or more.

\section{RESULTS}

\author{
$C^{14}$-Tyrosine Incorporation in the Lobster Cuticle During and After \\ a Molt \\ $\mathrm{C}^{14}$-tyrosine incorporation occurred in a time-dependent \\ manner, decreasing from 34,800 DPM after a molt to 16,000
}




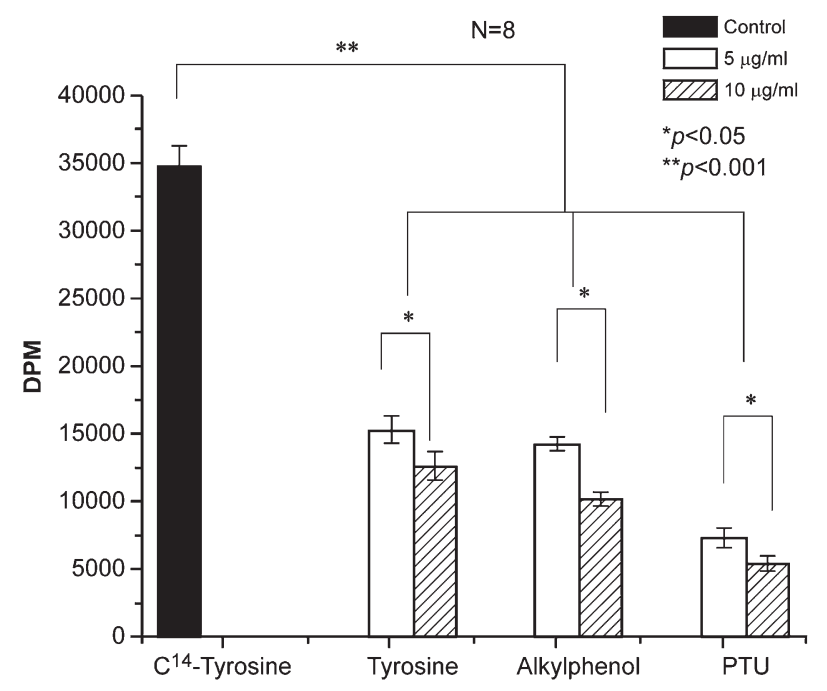

Figure 3. Cuticle $\mathrm{C}^{14}$-tyrosine incorporation inhibited by 2,4-bis-(dimethylbenzyl) phenol (alkylphenol), cold tyrosine, and phenylthiourea into a lobster cuticle during a molt (data from 3 experiments). $\left({ }^{*} p<0.05,{ }^{* *} p<0.001\right)$.

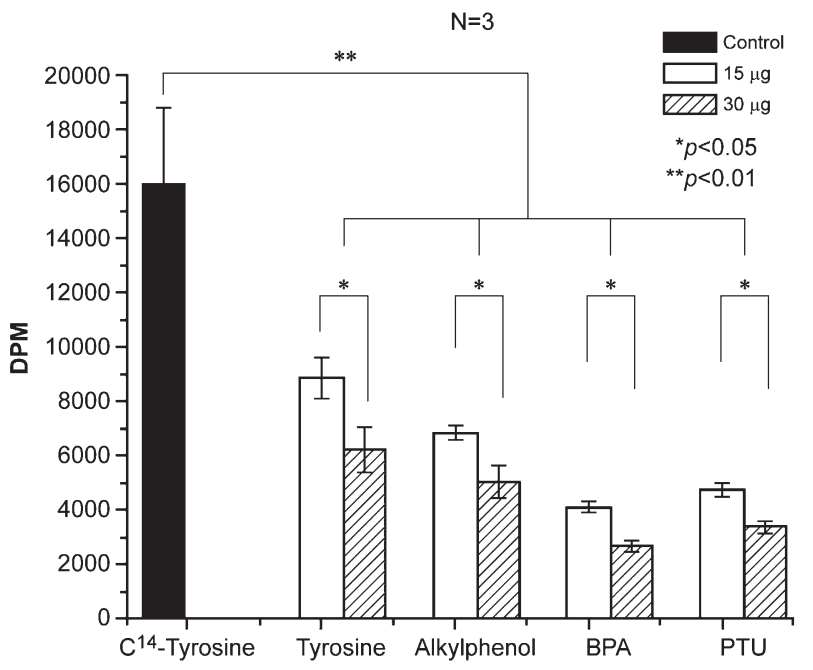

Figure 4. $C^{14}$-tyrosine incorporation and its inhibition by cold tyrosine 2,4bis-(dimethylbenzyl) phenol, BPA, and phenylthiourea (PTU) into new cuticle 1 day after a molt (data from 3 experiments). $\left({ }^{*} p<0.05,{ }^{* *} p<0.01\right.$ ).

DPM at day 1, less than 10,000 DPM by day 2, and 2,200 DPM at 4 days after a molt, for a total decrease of $93.5 \%$ (Figs. 3-6) $(P<0.01$ for each day after the molt compared with the day of the molt). This was also observed for the competitors such as alkylphenol (compound 3 (Figs. 3-6) and BPA (Figs 4 and 5)) and PTU. For example, $30 \mu \mathrm{M}$ (or $10 \mu \mathrm{g} / \mathrm{mL}$ ) alkylphenol treatment after a molt showed 14,100 DPM and decreased to 6,800 DPM by 2 days after a molt (decrease of $51.7 \%$ ), and finally to 1,600 DPM by 4 days after a molt (a decrease of $88.7 \% ; P<0.01)$.

Cold tyrosine competed significantly with $C^{14}$-tyrosine incorporation in the cuticle after a molt $(P<0.01)$, decreasing $\mathrm{C}^{14}$-tyrosine incorporation to $15,000 \mathrm{DPM}$ at $27.5 \mu \mathrm{M}(5 \mu \mathrm{g} / \mathrm{mL})$ cold tyrosine in comparison with 34,800 DPM for the untreated (decreased by $56 \%$ ). Competition was also concentration dependent as $10 \mu \mathrm{M}(55 \mu \mathrm{g} / \mathrm{mL})$ cold tyrosine decreased $\mathrm{C}^{14}$ -

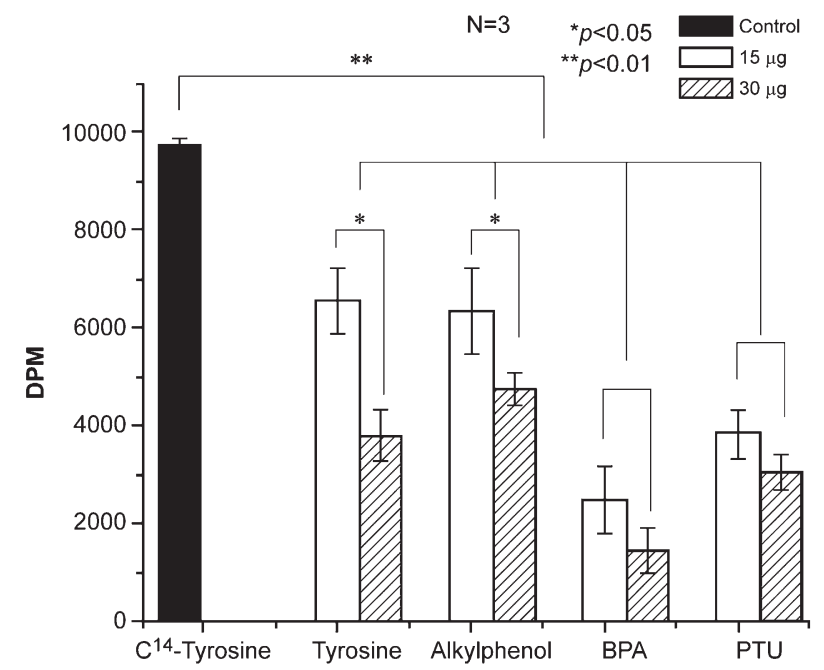

Figure 5. $C^{14}$-tyrosine incorporation and its inhibition by compounds into new cuticle 2 days after a molt (data from 3 experiments). ( ${ }^{*} p<0.05$, $* * \boldsymbol{p}<\mathbf{0 . 0 1})$.

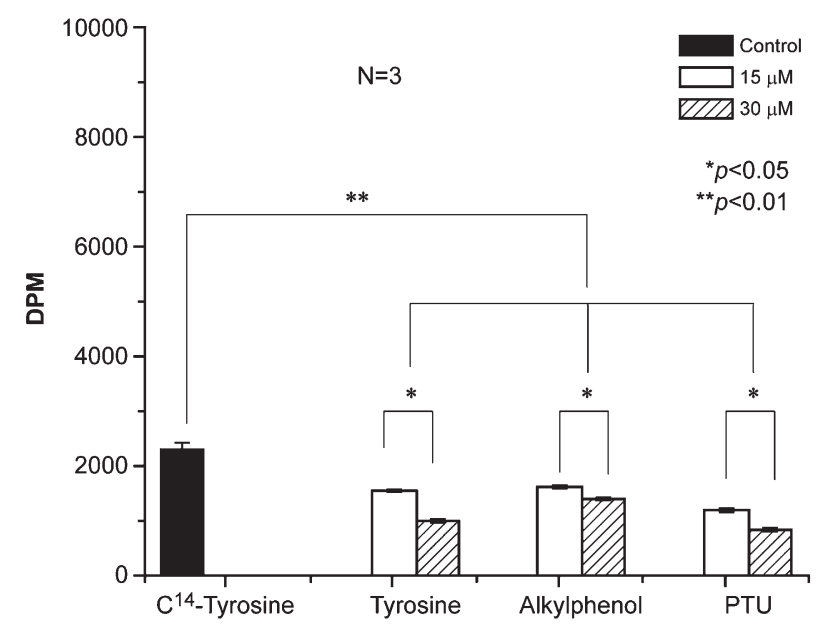

Figure 6. $\mathrm{C}^{\mathbf{1 4}}$-tyrosine incorporated into lobster shell (4 days after a molt), and its inhibition by several compounds (data from 3 experiments). $\left({ }^{*} p<\right.$ $0.05, * * p<0.01$ ).

tyrosine incorporation in the cuticle by $63.9 \%$ (Fig. 3). Similar concentration-dependent inhibitory effects were observed 1,2, and 4 days after a molt (Figs. $4-6)(P<0.01)$.

As expected, in nonmolting cuticle, untreated and treated cuticles showed no significant $\mathrm{C}^{14}$-tyrosine incorporation (Fig. 7) $(P>0.05)$.

\section{$C^{14}$-Tyrosine Incorporation Is Inhibited in Lobster Cuticle by Alkylphenol (Compound 3) Competition}

The alkylphenolic compound-2,4-bis-(dimethylbenzyl) phenol (compound 3)-also competed in a concentrationdependent manner with $\mathrm{C}^{14}$-tyrosine incorporation (Figs. 3-6) $(P<0.01)$. During a molt and 1 day after a molt, compound 3 exhibited a greater degree of competition than that of cold tyrosine ( $71 \%$ vs. $56 \%$ after a molt and $57 \%$ vs. $44 \%$ for 1 day after a molt; Figs. 3 and 4). 


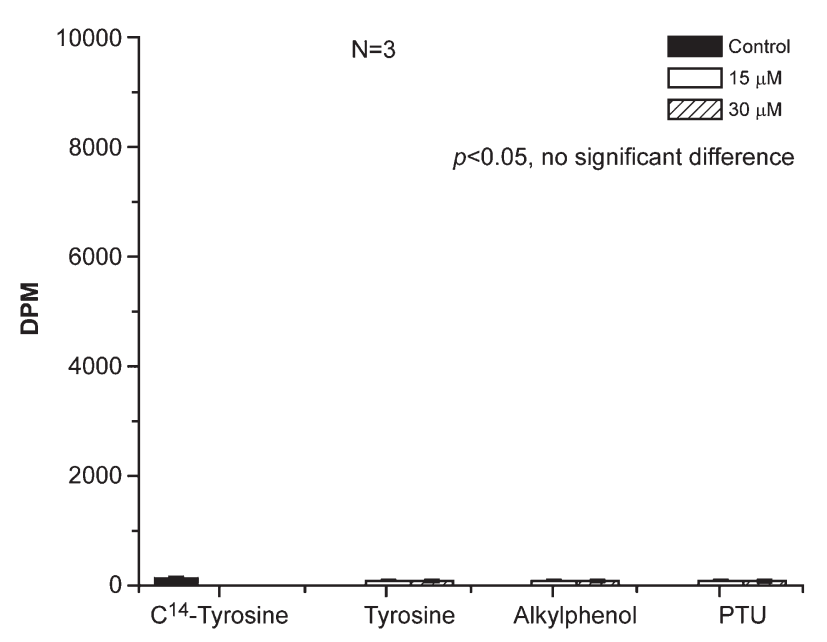

Figure 7. $\mathrm{C}^{14}$-tyrosine incorporated in nonmolting lobster shell (data from 3 experiments). $(p>0.05)$.

\section{$C^{14}$-Tyrosine Incorporation Is Inhibited in Lobster Cuticle by PTU}

PTU, a phenoloxidase inhibitor, exhibited a concentrationdependent inhibition of $\mathrm{C}^{14}$-tyrosine incorporation in the cuticle $(P<0.01$ during a molt $)$. PTU's high level of inhibition decreased over time after a molt, but even at 4 days after a molt, inhibition was still high $(79 \%$ after a molt to $48 \%$ at 4 days after a molt; Figs. 3-6). These results support the concept that tyrosine incorporation into the cuticle is phenoloxidase dependent.

\section{$C^{14}$-Tyrosine Incorporation Is Inhibited in Lobster Cuticle by BPA Competition}

Another alkylphenol, BPA, exhibited the greatest level of concentration-dependent inhibition of $\mathrm{C}^{14}$-tyrosine incorporation in the cuticle. At 1 day after a molt, there was a $74 \%$ inhibition (or 4,100 DPM in comparison with 16,000 DPM for untreated cuticle; $P<0.01$ ), and it did not decrease with time, as the DPM count was similar at 2 days after a molt (Figs. 4 and 5). In comparison, this inhibition is greater than the established phenoloxidase inhibitor PTU. At 1 day after a molt, $\mathrm{C}^{14}$-tyrosine incorporation in the cuticle for the untreated was 16,000 DPM whereas $15-\mu \mathrm{M}$ BPA and PTU treatments resulted in 4,100 DPM and 4,800 DPM C $\mathrm{C}^{14}$-tyrosine incorporation, respectively. At 2 days after a molt, $\mathrm{C}^{14}$-tyrosine incorporation for the untreated cuticle was 9,700 DPM whereas $15 \mu \mathrm{M}$ BPA and PTU resulted in 2,500 DPM and 3,800 DPM, respectively $(P<0.01)$. Similar inhibitions were also observed for 30- $\mu \mathrm{M}$ BPA (2,500 DPM and 1,000 DPM, respectively, for 1 and 2 days after a molt; $P<0.01$ ) and PTU treatments. These results are significant because, for the first time, they establish that BPA is a potent inhibitor of tyrosine incorporation in the cuticle, and its inhibitory activity is greater than that of the known enzyme inhibitor PTU.

\section{$C^{14}$-2,4-Bis-(Dimethylbenzyl) Phenol Incorporation in the Cuticle and the Inhibitory Effects of Competitors During a Molt}

$\mathrm{C}^{14}$-compound 3 was synthesized, and in vitro assays were carried out to study uptake and competition of incorporation in the cuticle during a molt. Cold alkylphenol inhibited $\mathrm{C}^{14}$-alkylphenol incorporation significantly $(P<0.01)$ in a concentration-dependent manner (9,500 DPM for untreated

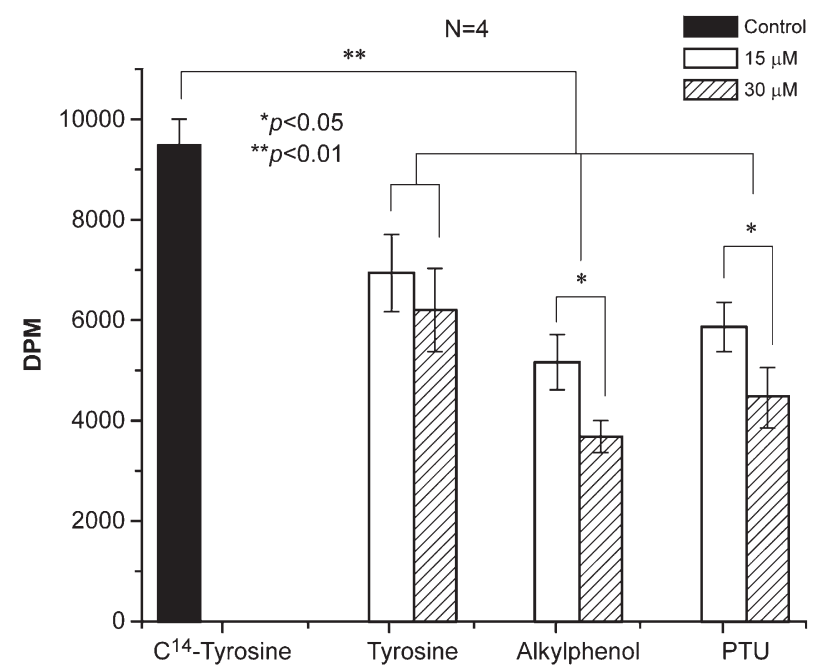

Figure 8. Cuticle $\mathrm{C}^{14}$-alkylphenol incorporation inhibition by cold alkylphenol, cold tyrosine, and phenylthiourea during a molt (data from 4 experiments). ( ${ }^{*} p<0.05, * * p<0.01$ ).

to 5,100 DPM and 3,700 DPM for $15 \mu \mathrm{M}$ and $30 \mu \mathrm{M}$ alkylphenol, or inhibition of $46 \%$ and $61 \%$, respectively; Fig. 8). Tyrosine exhibited a $27 \%$ and $34.5 \%$ inhibition at $15 \mu \mathrm{M}$ and $30 \mu \mathrm{M}$, respectively. Last, at $15-\mu \mathrm{M}$ and $30-\mu \mathrm{M}$ PTU treatments, inhibition of $\mathrm{C}^{14}$-alkylphenol incorporation was at $38 \%$ and $53 \%$, respectively $(P<0.01$; Fig. 8$)$. These results provide further evidence of this alkylphenolic compound incorporation in the cuticle after a molt, supporting the earlier findings of this alkylphenol as a competitor of tyrosine incorporation in the cuticle after a molt.

\section{In Vivo Alkylphenol Inhibition of Shell Hardening}

Lobsters were either treated with peanut oil (control) or alkylphenol (compound 3 in peanut oil) and were tested for shell hardening after a molt. A calibrated pressure gauge that exerts $5 \mathrm{lb}$ pressure was used on intact carapace shells of lobsters on various days after a molt. Although the control shells required 7.1 days $(n=15)$ to harden sufficiently to resist deformation by the pressure gauge, the treated shells needed 12.1 days $(n=9)$ to resist the same pressure $(P<0.01$; Fig. 9$)$. Furthermore, treated lobsters required an extra 17 days to molt, in comparison with their untreated counterparts. These studies show that alkylphenolic compound treatment noticeably inhibited and delayed molting as well as the postmolt-associated shell hardening process in lobsters.

\section{DISCUSSION}

We have presented evidence that 2 of the anthropogenic alkylphenols we detected in hemolymph and tissues of fieldcaught lobsters from all over southern New England, including LIS (Jacobs et al. 2008, Jacobs et al. 2012), interfered with shell hardening in lobsters by competing with tyrosine and its derivatives. This interference occurred during critical early steps of sclerotization (1-4 days). This effect was suggested previously in studies performed by several investigators in other invertebrate organisms (Sacher 1971, Zomer \& Lipke 1981, Semensi \& Sugumaran 1986). They showed that mosquito larvae treated with another alkylphenolic compound-MON0585 (2.6 bis-(t-butyl)-4(dimethylbenzylphenol), which we also 


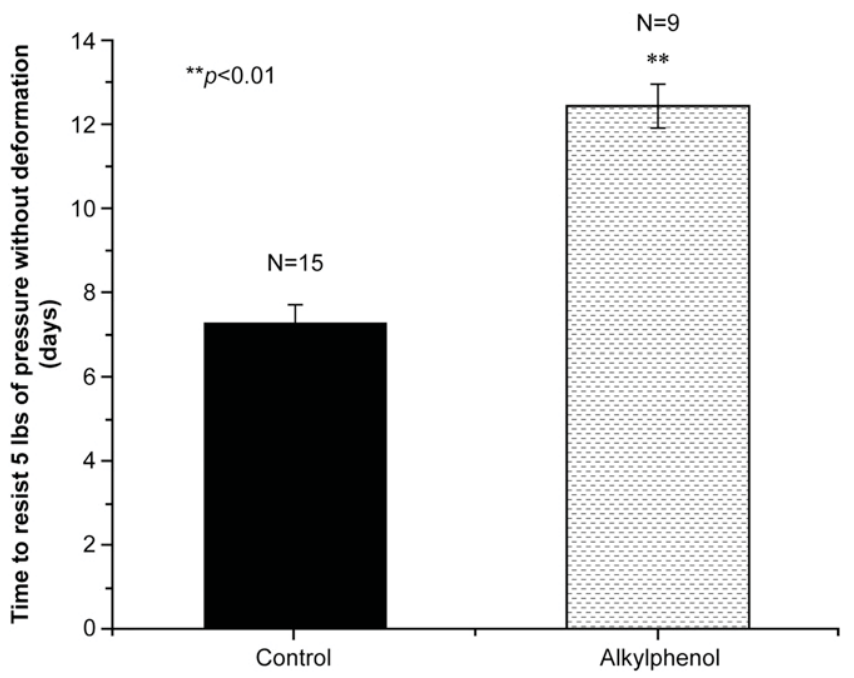

Figure 9. Inhibition of shell hardening (in days) after a molt by injection of compound 3, 2,4-bis-(dimethylbenzyl) phenol (alkylphenol), or peanut oil (control). $(* * p<0.01)$.

TABLE 1.

Tyrosine, 2,4-bis-(dimethylbenzyl) phenol (alkylphenol), and phenylthiourea equivalents.

\begin{tabular}{lccc}
\hline \hline & Tyrosine $(\boldsymbol{\mu M})$ & Alkylphenol $(\boldsymbol{\mu M})$ & Phenylthiourea $(\boldsymbol{\mu M})$ \\
\hline $5 \mu \mathrm{g} / \mathrm{mL}$ & 27.5 & 15 & 32.8 \\
$10 \mu \mathrm{g} / \mathrm{mL}$ & 55 & 30 & 65.6 \\
\hline
\end{tabular}

found in lobsters (Biggers \& Laufer 2004) - experienced 100\% mortality resulting from toxicity at metamorphosis at a concentration of $1 \mathrm{ppm}$. The larvae initiated the molt into the pupal stage, but although normal pupae were dark brown and hardened after cuticle sclerotization, treated larval pupae intermediates remained soft and were white. These results suggested that MON-0585 interfered specifically with metamorphosis, tanning, and cuticle hardening during the molting process.

The amino acid tyrosine is a phenol and plays a key role in the sclerotization (hardening and tanning) of the lobster cuticle (Fig. 1). During cuticle formation, tyrosine is metabolized by the enzyme tyrosinase or phenoloxidases to n-acetyl dopamine and then to a quinone (Sugumaran et al. 1992, Xu et al. 1997). If the tyrosine derivatives are replaced by alkylphenols, which have a more complex structure, there are fewer opportunities for protein or chitin cross-linking, thus weakening the shell.

We found that tyrosine and alkylphenols could incorporate into the new cuticle of lobsters, and that alkylphenols competed with tyrosine during the incorporation. As indicated in Table 1, $5 \mu \mathrm{g} / \mathrm{mL}$ and $10 \mu \mathrm{g} / \mathrm{mL}$ tyrosine are nearly 2 times the equivalent in concentration as that of the alkylphenol (compound 3). The data in Figure 3 suggest that alkylphenols outcompete tyrosine in the shell hardening reaction. This reaction is mostly dependent on the enzymatic activity of phenoloxidase, therefore resulting in less tyrosine incorporation. These data support our contention that alkylphenolic contamination interferes with shell hardening. We also found that $\mathrm{C}^{14}$-tyrosine did not incorporate into cuticle of nonmolting lobster, suggesting that tyrosine incorporation into lobster cuticle happens mostly during postmolt cuticle formation.
More important, these experiments provide clear evidence that alkylphenols, even at half the concentration as that of tyrosine, incorporate into the cuticle during shell hardening at a more competitive rate than tyrosine and its derivatives. These results are significant because, for the first time, they establish that BPA is a potent inhibitor of tyrosine incorporation in the cuticle, and its inhibitory activity is greater than that of the known enzyme inhibitor PTU.

Alkylphenols do not cross-link as successfully as tyrosine and its derivatives. This suggests that alkylphenols are taken up by molting cuticles. Alkylphenol-treated cuticle remains soft for extended periods of time. The possible reason may be that alkylphenol contamination affects the structural integrity of lobster shells. Sacher (1971) also described similar effect on mosquito larval cuticles which were prevented from sclerotizing and melanizing when treated with 1 ppm 2,5-bis-(t-butyl)-4(dimethylbenzylphenol) - an alkylphenol also known as MON 0585. Pupation and metamorphosis were interrupted in the mosquitoes because the dose was lethal at this stage. We also found (Laufer et al. 2012) that alkylphenols, both compound 3 and BPA, were toxic to larval lobsters before and at metamorphosis, and that they interfered with the normal larvaljuvenile transition by resulting in high percentages of intermediates among the few survivors.

The use of radioactive tyrosine and radioactive compound 3, 2,4-bis-(dimethylbenzyl) phenol, shows that these compounds are taken up by the cuticle. The use of nonradioactive competitors, including BPA, shows that these compounds compete with the uptake and incorporation of these radioactive compounds into the shell. The in vivo shell hardening experiment shows that there is a weakening effect of alkylphenols on the actual shell hardening process. Kunkel and Jercinovic (2012) suggest that the carbonate apatite structure of the lobster cuticle, which gives the shell its major strength, is dependent on proper protein cross-linking structures that are apparently disrupted here by substituting alkylphenols for tyrosine. An alteration of shell structure by contaminants such as alkylphenolic pollutants makes the shell weaker and may make the shells more susceptible to microbial invasion, thus possibly contributing to such phenomena as lobster shell disease. Increased susceptibility to shell disease would certainly affect the lobster population negatively, because it has been observed that ovigerous lobsters molt in defense of shell disease, discarding their embryos with their shell (Laufer et al. 2005a, Laufer et al. 2005b).

\section{ACKNOWLEDGMENTS}

This research was supported by the National Marine Fisheries Service as the New England Lobster Research Initiative: Lobster Shell Disease under NOAA grant NA06NMF4720100 to the University of Rhode Island Fisheries Center. The views expressed herein are those of the authors and do not necessarily reflect the views of NOAA or any of its subagencies. The U.S. government is authorized to produce and distribute reprints for government purposes, notwithstanding any copyright notation that may appear hereon. The research was also supported by grants from the Connecticut Sea Grant College Programs, NOAA, the Connecticut Department of Environmental Protection, the University of Connecticut Research Foundation, and the Marine Biological Laboratory, Woods Hole, MA. We thank Bro Coté; University of Rhode Island 
Fisheries Center staff; Massachusetts Department of Fisheries for lobster collections; Thomas Angell, Robert Glenn, and Penny Howell for providing lobsters for our research; Dr. Donald F. Landers, Jr., for supplying annual Millstone environmental laboratory reports, and lobsters; and Kathleen Castro and Barbara Somers for providing us with lobsters and administrative support. All of their assistance is very much appreciated.

\section{LITERATURE CITED}

Biggers, W. J. \& H. Laufer. 1996. Detection of juvenile hormone-active compounds by larvae of the marine annelid Capitella sp. I. Arch. Insect Biochem. Physiol. 32:475-484.

Biggers, W. J. \& H. Laufer. 1999. Settlement and metamorphosis of Capitella larvae induced by juvenile hormone-active compounds is mediated by protein kinase C and ion channels. Biol. Bull. 196:187-198.

Biggers, W. J. \& H. Laufer. 2004. Identification of juvenile hormoneactive alkylphenols in the lobster Homarus americanus and in marine sediments. Biol. Bull. 206:13-24.

Calafat, A. M., Z. Kuklenyik, J. A. Reidy, S. P. Caudill, J. Ekong \& L. L. Needham. 2005. Urinary concentrations of bisphenol A and 4-nonylphenol in a human reference population. Environ. Health Perspect. 113:391-395.

Crain, D. A., M. Eriksen, T. Iguchi, S. Jobling, H. Laufer, G. A. LeBlanc \& L. J. Guillette. 2007. An ecological assessment of bisphenol-A: evidence from comparative biology. Reprod. Toxicol. 24:225-239.

David, A., H. Fenet \& E. Gomez. 2009. Alkylphenols in marine environments: distribution monitoring strategies and detection considerations. Mar. Pollut. Bull. 58:953-960.

Dillaman, R., S. Hequembourg \& M. Gay. 2005. Early pattern of calcification in the dorsal carapace of the blue crab, Callinectes sapidus. J. Morphol. 263:356-374.

Hale, R. C., C. L. Smith, P. de-Fur, E. Harvey, E. Bush, M. J. La-Guardia \& G. G. Vadas. 2000. Nonylphenols in sediments and effluents associated with diverse wastewater outfalls. Environ. Toxicol. Chem. 19:946-952.

Jacobs, M., H. Laufer, J. D. Stuart, M. Chen \& X. Pan. 2008. Alkylphenols and Lobsters in Long Island Sound: Patterns, Mechanisms, and Consequences. In: 9th Biennial Long Island Sound Research Conference Proceedings. Long Island Sound Foundation, New London, CT. pp. 43-50.

Jacobs, M., H. Laufer, J. D. Stuart, M. Chen \& X. Pan. 2012. Endocrine disrupting alkylphenols are widespread in the blood of lobsters from southern New England and adjacent offshore areas. J. Shellfish Res. 31:563-571.

Kunkel, J. G. \& M. J. Jercinovic. 2012. Carbonate apatite in cuticle structure adds resistance to microbial attack for American lobster. Mar. Biol. Res. (In press).

Langford, K. H., M. D. Scrimshaw \& J. N. Lester. 2007. The impact of process variables on the removal of PBDEs and NPEOs during biological sewage treatment. Arch. Environ. Contam. Toxicol. 53:1-7.

Laskin, J. D. \& L. A. Piccinini. 1986. Tyrosinase isozyme heterogeneity in differentiating B16/C3 melanoma. J. Biol. Chem. 261:16626-16635.

Laufer, H., B. Baclaski \& U. Koehn. 2012. Alkylphenols affect lobster (Homarus americanus) larval survival, molting and metamorphosis. Invertebr. Reprod. Dev. 56:66-71.

Laufer, H., D. Borst, F. C. Baker, C. Carasco, M. Sinkus, C. C. Reuter, L. W. Tsai \& D. A. Schooley. 1987. Identification of a juvenile hormone-like compound in a crustacean. Science 235:202-205.

Laufer, H., N. Demir \& X. Pan. 2005a. Response of the American lobster to the stress of shell disease. J. Shellfish Res. 24:757-760.

Laufer, H., N. Demir \& X. Pan. 2005b. Shell disease in the American lobster and its possible relation to alkylphenols. In: M. F. Tlusty, H. O. Halvorson, R. Smolowitz \& U. Sharma, editors. State of lobster science: shell disease workshop. Aquatic Forum Series 05-1. Boston, MA: New England Aquarium. pp. 72-75.

Markey, C. M., C. L. Michaelson, C. Sonnenschein \& A. M. Soto. 2001. Alkylphenols and bisphenol A as environmental estrogens. In:
M. Metzler, editor. The handbook of environmental chemistry. Vol. 3, part L. Berlin, Heidelberg: Springer. pp. 129-153.

Matthews, C. K. \& K. E. Van Holde. 1990. Biochemistry. Redwood City, CA: Benjamin/Cummings Publishing. 724 pp.

Meyers, J. P., F. S. vom Saal, B. T. Akingbemi, K. Arizono, S. Belcher, T. Colborn, I. Chahoud, D. A. Crain, F. Farabollini, L. J. Guillette, T. Hassold, S. M. Ho, P. A. Hunt, T. Iguchi, S. Jobling, J. Kanno, H. Laufer, M. Marcus, J. A. McLachland, A. Nadal, J. Oehlmann, N. Olea, P. Palanza, S. Parmigiani, B. S. Rubin, G. Schoenfelder, C. Sonnenschein, A. M. Soto, C. E. Talsness, J. A. Taylor, L. N. Vandenberg, J. G. Vandenberg, S. Vogel, C. S. Watson, W. V. Welshons \& R. T. Zoeller. 2009. Why public health agencies cannot depend on Good Laboratory Practices as a criterion for selecting data: the case of bisphenol A. Environ. Health Perspect. 117:309-315.

Mihaich, E. M., U. Friederich, N. Caspers, A. Hall, G. M. Kleqka, S. S. Dimond, C. A. Staples, L. S. Ortego \& S. G. Hentges. 2009. Acute and chronic toxicity testing of bisphenol A with aquatic invertebrates and plants. Ecotoxicol. Environ. Saf. 72:1342-1399.

Millstone Environmental Laboratory. 2008. Annual report. Monitoring the marine environment of Long Island Sound at Millstone Power Station, Waterford, Connecticut: Dominion Resources Services, Inc. pp. 189-221.

Naylor, C., J. Mieure, W. Adams, J. Weeks, F. Castaldi, L. Ogle \& R. Romano. 1992. Alkylphenol ethoxylates in the environment. J. Am. Oil Chem. Soc. 69:695-703.

Pantin, C. F. A. 1934. On the excitation of crustacean muscle. I. J. Exp. Biol. 11:11-27.

Renner, R. 1997. European bans on surfactant trigger transatlantic debate. Environ. Sci. Technol. 31:316A-320A.

Riddiford, L. M. \& P. D. Evans. 1994. Cellular and molecular actions of juvenile hormone I: general considerations and premetamorphic actions. In: P. D. Evans, editor. Advances in insect physiology. San Diego, CA: Academic Press. pp. 213-274.

Sacher, R. M. 1971. A mosquito larvicide with favorable environmental properties. Mosq. News 31:513-516.

Semensi, V. \& M. Sugumaran. 1986. Effect of MON-0585 on sclerotization of Aedes aegypti cuticle. Pestic. Biochem. Physiol. 26:220-230.

Sugumaran, M., V. Semensi, B. Kalyanaraman, J. M. Bruce \& E. J. Land. 1992. Evidence for the formation of a quinone methide during the oxidation of the insect cuticular sclerotizing precursor 1,2dehydro-N-acetyldopamine. J. Biol. Chem. 267:10355-10361.

Vacca, L. L. \& M. Fingerman. 1975a. The mechanism of tanning in the fiddler crab, Uca pugilator-I: tanning agents and protein carriers in the blood during ecdysis. Comp. Biochem. Physiol. B 51:475-481.

Vacca, L. L. \& M. Fingerman. 1975b. The mechanism of tanning in the fiddler crab, Uca pugilator-II: the cyclic appearance of tanning agents and attached carrier proteins in the blood during the molting cycle. Comp. Biochem. Physiol. B 51:483-487.

Vacca, L. L. \& M. Fingerman. 1983. The roles of hemocytes in tanning during the molting cycle: a histochemical study of the fiddler crab, Uca pugilator. Biol. Bull. 165:758-777.

vom Saal, F. S., B. T. Akingbemi, S. M. Belcher, L. S. Birnbaum, D. A. Crain, M. Eriksen, F. Farabollini, L. J. Guillette, Jr., R. Hauser, J. J. Heindel, S. M. Ho, P. A. Hunt, T. Iguchi, S. Jobling, J. Kanno, R. A. Keri, K. E. Knudsen, H. Laufer, G. A. LeBlanc, M. Marcus, J. A. McLachlan, J. P. Myers, A. Nadal, R. R. Newbold, N. Olea, G. S. Prins, C. A. Richter, B. S. Rubin, C. Sonnenschein, A. M. Soto, C. E. Talsness, J. G. Vandenbergh, L. N. Vandenberg, D. R. Walser-Kuntz, 
C. S. Watson, W. V. Welshons, Y. Wetherill \& R. T. Zoeller. 2007. Chapel Hill bisphenol A expert panel consensus statement: integration of mechanisms, effects in animals and potential to impact human health at current levels of exposure. Reprod. Toxicol. 24:131-138.

Warhurst, A. M. 1995. An environmental assessment of alkylphenol ethoxylates and alkylphenol. J. Appl. Ecol. 32:890-905.

Welch, L. H. \& N. L. Drake. 1938. The condensation of some tertiary aryl substituted carbinols with phenol in the presence of aluminum chloride. Am. Chem. Soc. 60:59.
Xu, R., X. Huang, T. L. Hopkins \& K. J. Kramer. 1997. Catecholamine and histidyl protein cross-linked structures in sclerotized insect cuticle. Insect Biochem. Mol. Biol. 27:101-108.

Ying, G. G., B. Williams \& R. Kookana. 2002. Environmental fate of alkylphenols and alkylphenol ethoxylates: a review. Environ. Int. 28:215-226.

Zomer, E. \& H. Lipke. 1981. Tyrosine metabolism in Aedes aegypti: arrest of sclerotization by MON 0585 and diflubenzuron. Pestic. Biochem. Physiol. 16:28-37. 